Dodging pressure by avoiding control: debates concerning the 'law of captivity' (the 'War of the Hornets' in Pernambuco, 1851-1852).

\section{Sobreviver à pressão escapando ao controle: embates em torno da "lei do cativeiro" (a Guerra dos Marimbondos em Pernambuco, 1851-1852).}

Maria Luiza Ferreira de Oliveira

Pós-doutoranda do Instituto de Estudos Brasileiros da Universidade de São Paulo

\section{Resumo}

0 comentário ao texto de Guillermo Palacios está feito em torno de duas questões principais, a primeira é o problema da pressão pela mão de obra livre no contexto da expansão do açúcar e a segunda são as razões para o fim do movimento (a chamada 'Guerra dos Marimbondos'). Debatemos com o texto de Palacios a duração e a circunscrição espacial da revolta, o que traz conseqüências para uma das teses de seu trabalho, que entende tratarse de luta camponesa restrita aos meses mortos da produção agrícola. A atuação do governo na repressão ao movimento e o papel do frei capuchinho Caetano de Messina são também discutidos, buscando averiguar o enquadramento político dos embates ocorridos entre dezembro de 1851 e fevereiro de 1852.

\section{Abstract}

The present text addresses two central issues of Guillermo Palacios' paper, first the pressure towards the use of free labor in the context of the sugar industry growth and, secondly, the reasons that explain the end of the rebellious movement (the so called 'War of the Hornets'). By dealing with the length and the geographical limits of the rebellion, aspects that are both central to Palacios argument, the text aims to debate the author's interpretation of the movement as a peasant rebellion restricted to a nonharvest period. The government's response regarding the rebellion's defeat and the role played by a Capuchin Monk, Friar Caetano de Messina, are also discussed in order to place in a broader political scenario the events that occurred between December 1851 and February 1852.

\section{Palavras-chave}

homens livres pobres, revolta / rebelião, Pernambuco, Segundo Reinado, agricultura, modernização

\section{Keywords}

poor free people, uprising / rebellion, Pernambuco, Second Reign, agriculture, modernization 
Fiz o levantamento documental em Recife para minha pesquisa de pós doutorado realizada no IEB/USP e financiada pela Fapesp desde março de 2005.
"É certo que nos achamos sobre a cratera de um vulcão. V.Excia providenciará convenientemente". Nazareth da Mata, 3 de janeiro de 1852. O Juiz de Direito Joaquim Manoel Vieira da Mota, em carta ao P. P. Pernambuco, Dr.Vitor de Oliveira.

\section{Preâmbulo}

São raros os estudos sobre as revoltas populares no Brasil do século XIX, ainda mais com o olhar para os atores sociais diretamente envolvidos na luta, escapando da visão dominante de que os pobres seriam apenas massa de manobra, sem reivindicações próprias. Mais raros ainda são os estudos sobre a Guerra dos Marimbondos, movimento considerado inexpressivo, justamente dominado pela "ralé". 0 trabalho de Palacios resgata os homens livres pobres como sujeitos da história. Certamente se tivesse sido publicado vinte anos atrás, quando foi escrito, a historiografia dos homens livres pobres no Brasil teria avançado bem mais rapidamente.

São muitas as discussões que o texto suscita. Meu comentário ficará diretamente preso às questões levantadas pela leitura dos documentos'

\section{Controle da mão de obra}

$\mathrm{Na}$ narrativa dos acontecimentos Palacios esboça um desenho para o encaminhamento dos episódios, pensa uma evolução que se traduz em um trajeto, um mapa dos eventos. Nesse quadro, a revolta começou e terminou em Paudalho, vila que junto com Nazaré e Limoeiro formaram o palco principal da Guerra dos Maribondos. Esse desenho traz também uma diferenciação dos padrões da revolta em cada uma das regiões - Mata seca (triângulo), mata norte, mata sul, agreste, sertão - assim como de graus de intensidade - decrescentes do triângulo ao sertão. E esse mapa contém um sentido explicativo, que corrobora a tese central do trabalho.

Na minha leitura a revolta pareceu mais simultânea nas diversas localidades, menos diferenciada em seus padrões mas não em sua intensidade e, sobretudo, mais dilatada, entrando fevereiro adentro. Se Garanhuns, no agreste, foi invadida só em 26 de janeiro, outras localidades da região sofreram abalos bem antes, como foi o caso de Flores, no sertão norte, próximo à fronteira com a Paraiba, no dia 28 de dezembro. A cabeça de Comarca Paudalho foi ocupada no dia 1 de janeiro, ao mesmo tempo em que Buíque, povoação da Comarca de Garanhuns, mas bem distante desta sertão adentro, era ocupada por cinqüenta homens fortemente armados que ameaçaram a vida do vigário, assim como Jaboatão, nas portas do Recife, era, por sua vez, ocupada por 400 homens. A impressão é que a revolta foi dispersa e simultânea na mata seca, mata norte, sertão, mata sul, e apresentou mais ou menos o mesmo padrão, engenhos foram atacados na mata norte, mas também em Nazaré, assim como em Limoeiro.

Uma das questões centrais para Palacios entender a revolta está na pressão do mercado de trabalho, pressão dos fazendeiros sobre os homens livres, devido à expansão do açúcar e da queda no algodão, realidade sobretudo na mata seca. E de fato foram os únicos locais onde houve ocupação das vilas. Mas a revolta não se concentrou nessas regiões, tampouco acabou quando Paudalho foi pacificada, e afetou, desde o início, regiões ainda distantes dessa pressão pela terra, como é o caso das vilas no sertão, ou mesmo de Garanhuns, onde a produção em pequena propriedade era muito significativa. 
APEJE, JP12, fl.95, 21/dez/1851, 20. Distrito de Paz da Freguesia de Santo Antão. APEJE, PC39, fl.70, Nazaré, 11/jan/1852, Del. Guilhermino Clemente Marques Bacalhao.

Evaldo Cabral de Melo, 0 norte agrário e o Império, Rio de Janeiro, Nova Fronteira, 1984 Guillermo Palacios, "Campesinato e escravidão: uma proposta de periodização para a história dos cultivadores pobres livres no Nordeste oriental do Brasil, c.1700-1875", Dados, 30:3 (1987), p345-353; Peter Eisemberg, Modernização sem mudança: a indústria açucareira em Pernambuco, 1840-1910. Rio de Janeiro, Paz e Terra, 1977; J. H. Galloway, The sugar cane industry : an historical geography from its origins to 1914, Cambridge [England]; New York: Cambridge University Press, 1989; Marcus J. M. de Carvalho, Liberdade, rotinas e rupturas do escravismo, Recife, 1822-1850, Recife, Editora da UFPE, 2002, p144-149.

B. J. Barickman, "Até a véspera: o trabalho escravo e a produção de açúcar nos engenhos do recôncavo baiano (1850-1881)", Afro-Ásia, v. 21-22, 1998-99. p.177-237.

APEJE, PC40, fl.169, 15/fev/1852, Ipojuca.

B. J. Barickman, "Até a véspera...", p.199.

Robert W. Slenes, "Confidence and Crisis in a Pecualiar Market:..., 1850-1888", Comunicação apresentada no Domestic Passages: Internal Slave Trades in the Americas, Yale University, 22 a 24 de outubro, 1999.

B. J. Barickman. "Até a véspera: o trabalho escravo e a produção de açúcar nos engenhos do recôncavo baiano (1850-1881)", Afro-Ásia, v. 21-22, 1998-99.
Havia sim uma pressão, o que pode explicar porque a revolta foi mais forte em Paudalho, mas ela ainda não resultava em controle - a população tinha todavia alguma independência e brigava por ela - não foi a toa que o governo capitulou. Fica muito evidente na documentação o temor das autoridades locais com relação a esses setores, a dificuldade do domínio, a necessidade de pactuar como sendo ainda a maior - não podiam ser tratados como escravos, e deixam isso claro. No meu entender ainda se mostram homens pobres livres: estão armados, andando de um lado para o outro, se fazendo ouvir, contam com o apoio dos efetivos da própria Guarda Nacional, ou seja, tem muito a seu favor. 0 massacre viria décadas depois.

O Juiz de Paz da Freguesia de Vitória de Santo Antão e também senhor do Engenho da Ronda, Felix Ferreira de Moraes, afirmou que:

"fique certo VE que, se eu pudesse contar com algumas pessoas que tenho ao redor de mim, não faria mais do que participar a VE o que fica exposto, mas não tendo em quem confie para a defesa desta, pois que as pessoas do povo, quer de um e quer de outro partido se mostram unidas no pensamento de obstarem ao cumprimento da lei em questão-21dez". 2

Vinte dias depois era a vez do Delegado de Nazaré:

"O Engenho Pindoba, Floresta, Urubu, Cipoal e outros lugares foram varejados por pequenos grupos que procuravam armamento e munições. Não tenho podido conter esses sediciosos porque a gente de que posso dispor também está fazendo parte desses anarquistas" 3.

Para esses homens admitirem em correspondência oficial que não dominavam os homens livres e pobres do lugar, é sinal que a situação estava mesmo difícil.

A historiografia consagrou que a transição para a mão de obra livre em Pernambuco foi suave e precoce (os trabalhos de Palácios, P. Eisemberg, Evaldo Cabral, Galloway ${ }^{4}$ ), e de maneira muito mais tranqüila do que na Bahia (Barickman5). Não temos como questionar a presença do trabalho livre nos engenhos na segunda metade do século XIX, mas de qualquer forma não parecia ser uma incorporação assim tão fácil, pelo menos no período da revolta.

Com dados demográficos sobre o número de livres em cada uma das comarcas envolvidas, assim como se fosse feito um estudo com inventários locais e sobretudo se tivéssemos como documentar a migração, poderiamos aprofundar ou matizar essa questão.

A escravidão era, de toda forma, ainda muito presente - embora estivesse decaindo. Os principais engenhos contavam com mão de obra escrava. Em consulta que o presidente da Província fez em 1852 aparece a relação de engenhos da comarca de Ipojuca, mata sul, uma das principais regiões produtoras de açúcar. Ali vemos engenhos com 120, 80, 60 escravos ${ }^{6}$, enquanto a média para os anos 1816-17 em Santo Amaro e São Francisco do Conde, no recôncavo, era de 65,5 escravos por engenho, segundo dados de Barickman?.

0 grande aumento de entrada de escravos na década de 1840 garantia sobrevida ao sistema mesmo com o fim do tráfico; de fato, estudos recentes indicam a presença de escravos no setor exportador ${ }^{8}$ ainda na década de 1880 na Bahia ${ }^{9}$. A maciça presença do braço escravo nas fazendas de café de São Paulo e de Minas era notória - as províncias "que emperravam a abolição". 
10

"Os interesses no sentido da manutenção da escravidão e do tráfico estiveram entre os vetores mais importantes da manutenção da unidade territorial e da solução dinástica, fazendo dela mais construção do que herança", Wilma Peres Costa, "0 império do Brasil, dimensões de um enigma", texto para discussão no projeto Temático, no prelo para publicação.

11

Maria Lúcia Lamounier, Da escravidão ao trabalho livre. A lei de locação de serviços de 1879. Campinas (SP), Papirus, 1988.

12

Hebe Maria Mattos, Das Cores do Silêncio os significados da liberdade no sudeste escravista. Rio de Janeiro, Nova Fronteira, 1998, passim.

13

Judy Alice Bieber Freitas, Marginal Elites: Politics, power Marginal Elites: Politics, power, and patronage in the backlands of northern Minas Gerais, Brazil, 1830-1889, Tese de doutorado, John Hopkins University, Baltimore, Maryland, 1994. pp. 335 e ss.
A necessidade da manutenção da escravidão na década de 1850 era não apenas uma unanimidade entre os grandes proprietários rurais mas também passava por ser uma questão de soberania nacional. Tratava-se de garantir a principal fonte de renda da jovem nação, assentada na economia agrícola de larga escala.

A questão com a Inglaterra na década de 1830 foi um marco nesse sentido. A pressão inglesa contra o tráfico criou um consenso que em matéria de mão de obra escrava era preciso agir de acordo com os interesses nacionais. A partir dali, vai ficando cada vez mais claro que as elites precisavam se unir para garantir o sistema. A manutenção da escravidão seria mesmo um dos pilares de sustentação da unidade nacional, em torno do qual elites escravistas de norte a sul se uniram ${ }^{10}$.

0 fracasso do projeto Ibicaba, por exemplo, mostra claramente a dificuldade que o setor de exportação teve para absorver outra forma de trabalho que não fosse o escravo, até pelo menos a década de 1880 (nesse período a vitória do projeto imigratório comprovou que para as elites locais o uso da mão de obra livre nacional era inviável).

A dificuldade de controlar e submeter a mão de obra livre ao regime de trabalho desejado pelo setor foi uma constante durante todo o século XIX.

No congresso agrícola de 1878 muitos proprietários pernambucanos reclamaram da dificuldade de lidar com a mão de obra livre. A pressão sobre o homem livre pobre ficaria de fato mais forte na década de 1880 e terrivel com o fim da escravidão. Daí o cerco se apertou. E se os homens livres sentiam-se ameaçados com a nova lei, não acho que seja o caso de dizer que a revolta era contra o fim da escravidão. Não há indício nesse sentido.

Um exemplo muito eloqüente da busca de algum domínio sobre a mão de obra livre é a lei de locação de serviços de 187911. Essa lei reflete com nitidez cristalina a dificuldade de controle dessa mão de obra e, ao mesmo tempo, a atuação do Estado nessa direção. Se o poder local não era suficiente, apelava-se ao Estado para isso; a lei foi aprovada em 1879 mas condensou certamente décadas de experiência e de posicionamento nesse sentido.

Parece que a questão fundamental que está em jogo é o medo, um medo coletivo de perder a condição da liberdade. A liberdade não era algo dado, constitutivo, para aqueles homens ela era condicional.

Os movimentos ocorridos em 1851 e 1852 sugerem uma das questões centrais no cotidiano das populações livres pobres no império: a vivência da instabilidade. No trabalho de Hebe Mattos vemos as negociações empreendidas por senhores e escravos pelos significados da liberdade; assim como as estratégias de inserção social dos libertos, seja através da família, da propriedade, da mobilidade, ou da condição de proprietário de escravo - dos mais eloqüentes signos da liberdade ${ }^{12}$.

Judy A. Bieber Freitas significativamente encontrou mais de 50 diferentes denúncias de escravidão ilegal de livres entre 1850 e 1860, todos nessa década, sendo que analisou o período de 1835-1889, no sertão mineiro. A maioria dos ilegalmente escravizados ia para a região cafeeira do sul. $E_{1}$ segundo pode constatar, autoridades municipais estavam largamente envolvidas no tráfico ilícito - capitães da Guarda Nacional, delegados, subdelegados e juizes municipais participaram ativamente no comércio, ou apenas fecharam os olhos ${ }^{13}$. 
14

Keila Grinberg, 0 fiador dos brasileiros. Cidadania, escravidão e direito civil no tempo de Antonio Pereira Rebouças. Rio de Janeiro, Civilização Brasileira, 2002, p. 77.
15

APEJE, PC39, fl.155, 26/jan/1852, Paudalho.
Vinte e poucos anos antes, em 1823, o já renomado advogado Antonio Pereira Rebouças, ao deixar a Bahia para encaminhar-se à Corte, enfrentou constrangimentos na estrada, tendo sido obrigado a prestar esclarecimentos sobre sua identidade, a defender-se relatando sua participação nas lutas pela independência na Bahia, nas quais se envolveu de corpo e alma. "Ou seja: se fosse apenas mulato, sem a fama dos recentes feitos, Rebouças provavelmente nem passaria da fronteira da província, ainda mais naqueles tempos, quando revoltas de escravos, libertos e outros pardos assustavam os engenhos da região. ${ }^{14 " ~ O s ~ r e c u r s o s ~ d e ~ d i f e r e n c i a c ̧ a ̃ o ~}$ de Rebouças, que depois the renderiam frutos na capital do Império, foram a profissão e ter participado nas guerras da independência, como ressalta Keila Grinberg.

Se Antonio Pereira Rebouças, já famoso, enfrentara problemas por ser mulato, não é difícil imaginar o cotidiano dos libertos e mulatos nessas décadas, sobretudo em Pernambuco, sacudido por ininterruptas revoltas.

Tinham medo, mas lutaram dando sua vida com convicção, pois sentiam que estavam perdendo direitos. E sua força era respeitada.

\section{0 fim do movimento}

Frei Caetano entra em Paudalho no dia 5 de janeiro, as tropas no dia 11, pacificando a vila. Limoeiro seria pacificada no dia 16, Palácios vê na pacificação dessas duas vilas o fim do movimento. A ocupação de Garanhuns já seria o canto do cisne, e os eventos posteriores seriam fatos isolados.

A paz já era cantada pelo Diário de Pernambuco desde 8 de janeiro, ao mesmo tempo em que 500 homens ocupavam Limoeiro. Mas a percepção da paz pelas autoridades locais era bem diferente. No dia 2 de fevereiro, depois do governo ter suspendido a execução do Decreto, 150 homens armados se juntavam nas proximidades de Vitória - das mais importantes cidades da região - pois o Juiz de Paz resolvera por novamente em execução o Decreto, e o padre começara a exigir as certidões. Como resultado, o juiz de paz acabou sendo assassinado. A população deixava bem claro que não tinha se acalmado. 0 Juiz de Direito mostrava grande preocupação pois além do crime e do ambiente de tensão, os inspetores de quarteirão da Comarca estavam abandonando seus postos, e nenhum suplente queria substituir o Juiz de Paz. Mas não era só em Vitória que a situação permanecia tensa, no dia 26 de janeiro, o Delegado de Paudalho dizia:

"Meu amigo e senhor, dou-lhe parte que se estão reunindo grupos armados na Gloria e fizeram esta noite duas mortes; (...) rogo-Ihe que como amigo arranje-me alguma munição para defender-me, (...) pois não posso mais sair, esta é a grande paz que dizem os diários (...) Antonio Pinto de Mattos 15 .

Enquanto pairava a ameaça do Decreto ser posto em prática, a população estava alerta e sobressaltada.

A meu ver há uma sobrevalorização da atuação do capuchinho no apaziguamento da revolta. Não que o texto do Palacios enfatize isso, o capuchinho aparece como um fator importante, mas não como único. A pequena historiografia e sobretudo o Diário de Pernambuco fez grande alarde da atuação do frade, descrevendo o júbilo da população, a recepção calorosa que ele teve em Paudalho e o sucesso total de sua missão. Mas mais uma vez as autoridades locais foram mais cautelosas: 
16

APEJE, PC40, fl.51, 11/jan/1852, Delegado supl. Francisco da Motta Cavalcante

\section{7}

Guillermo Palacios, "Messianismo e expropriação camponesa. Uma nova expedição ao Reino da Pedra Encantada do Rodeador, Pernambuco, 1820", Revista de História, n. 147, $2^{\circ}$ semestre de 2002 .

18

Mônica Duarte Dantas, Fronteiras movediças : relações sociais na Bahia do século XIX (a comarca de Itapicuru e a formação do arraial de Canudos), Doutorado, FFLCH-USP, 2002.
"No dia 5 pelas duas horas da tarde entrou nesta Vila o Missionário F. Caetano, que fez grande esforço a bem do sossego publico, e o continua a fazer, o qual esteve em perigo de vida porque alguns o entendiam como traidor! (...) porem os revoltosos estão muito audazes e são capazes das maiores atrocidades não havendo na vila força que os atine. Agora mesmo se me diz que em algumas partes os sediciosos (estão) a reunir grupos. 16"

0 frade ajudara a acalmar os ânimos, mas a situação era percebida como tensa seis dias após a sua chegada. Isso sem falar que alguns o consideraram traidor e ele chegou a correr perigo de vida, ou seja, nada daquela acolhida unânime. Mesmo com a presença do frade os rebeldes mataram duas pessoas.

Por um lado, parece que a população claramente não identificava o frade ao governo e reconhecia no missionário um possivel porta voz, mas havia também distanciamento, ou seja, não se tratava de fanáticos que ao simples aparecimento do "homem santo" deixariam tudo de lado, todas as reivindicações, como cordeiros de Deus. Não eram cordeiros, longe disso.

A historiografia sobre revoltas populares ou mesmo sobre populações livres e pobres no nordeste tende a destacar demasiadamente o papel da religião, deixando de lado os modos de vida e as relações sociais que teciam, ao mesmo tempo que não são estudadas as especificidades da religiosidade popular, das manifestações de cada grupo, em geral distantes da liturgia oficial da igreja católica. 0 próprio Palacios já mostrou em seu fundamental estudo sobre o Rodeador ${ }^{17}$, vista como uma revolta de fundo sagrado, quase de fanáticos, que os motivos eram bem terrenos. A crença messiânica estava longe de ser o principal motivo. Mônica Dantas quis escapar do senso comum que entendia Canudos como fruto do messianismo e desvendou todo um complexo universo social até então não abordado pela historiografia ${ }^{18}$.

Qual seria então a causa principal do fim da revolta? 0 recuo do governo, a ausência da principal ameaça. Mas o governo não queria enfatizar que tinha recuado, a ênfase não devia recair sobre a vitória dos matutos, e sim sobre a atuação do frade. E, mais importante, o gabinete que acabara de "pacificar" o país queria manter a sua fama de promotor da ordem. Ter isso em mente ajuda a responder a questão que vem em seguida: porque o governo recuou? Antes dela, queria debater um pouco sobre a atuação do governo durante a revolta.

Palacios fala em duas vertentes: "isolar os pretensos agitadores, identificando-os e prendendo-os e combater o efeito de suas ações por meio de táticas de dissuasão e apaziguamento". Isolar e prender os agitadores não me parece que tenha sido a estratégia adotada, foi recomendada pelas autoridades do centro (Recife), mas mais uma vez a percepção da realidade local pelas autoridades em serviço encaminhou a atuação de outra forma. Primeiro, todas as autoridades locais respondem da dificuldade de encontrar líderes da revolta. Era, diziam, uma "sedição de quase todo o povo", "sedição geral", "do povo mais miúdo". E mesmo depois, quando sabem dos crimes de assassinato ou roubos cometidos pelos revoltosos, e podem identificar seus autores, preferem não os pronunciar legalmente. E dizem isso textualmente! Ou seja, mostra não uma ação reativa, mas de asfixia, visando conter e dissipar a pressão. 0 Delegado de Paudalho é um dos que pondera:

"Acuso recebidos ontem os ofícios de VE (...) me ordena proceda contra os sediciosos, que cometeram crimes na recente revolta, o que 
19

APEJE, PC40, fl.89, 26/jan/1852, Delegado Francisco da Mota Cavalcante.

20

APEJE, PC39, fl.227, 9/fev/1852, Vitória, Delegado Joaquim Jorge dos Santos.

21

APEJE, PC40, fl.18, 2/jan/1852, Vitória, J. Direito Anselmo Francisco Peretti

22

Sobre o estado da guarnição na Bahia ver: $\mathrm{H}$. Kray, "O cotidiano dos soldados na guarnição da Bahia (1850-1889)", in Nova História Militar Brasileira, Rio de Janeiro: Editora Bom Texto / FGV, 2004, p.237-268.

23

APEJE, PC40, fl.11, 3/jan/1852, Buique, subdelegado Lourenço de Albuquerque Cavalcanti.

24

APEJE, PC40, fl.119, 3/fev/1852, Garanhuns, Del. Hemetrio José. obediente devendo e desejando cumprir, recorro a VE representando (...) parece-me que por ora deve-se paralisar para depois proceder-se contra os que durante a realização cometeram delitos; porquanto não obstante as Missões e relevantes serviços do Missionário, e o forte Destacamento da Vila, surgem boatos aterradores, e mesmo porque a Freguesia da Glória subsiste em completa anarquia"19.

0 Delegado de Vitória não recomendava sequer o pronunciamento pela morte do Juiz de Paz:

"Em tempo formarei o processo por esta morte, o que já não faço pela razão de que atento o estado das coisas, não haverão testemunhas que queiram depor, e se forem obrigados nada dirão" 20.

Tanto foi abafatória a reação que alguns representantes da lei reclamaram por mais brio e demonstração de autoridade. Especialmente o Juiz de Direito de Vitória mostrava-se sempre preocupado, não querendo que suspendessem o Decreto:

"(...) não só por que traz por conseqüência inexecução de uma lei, como porque acostuma o povo a insubordinação, e o prepara para qualquer desordem. (...) desejo ardente que nutro de ver a lei respeitada, mantendo-se entre os povos o respeito e obediência às autoridades como tanto convém, mormente numa província como esta, onde tem aparecido tão graves comoções." 21

Mas afinal porque as autoridades locais mostravam-se tão temerosas, sentindo-se ameaçadas e frágeis? Por trás dessa postura do governo está sem dúvida a dificuldade do aparelhamento militar e das formas de garantia da segurança pública 22.0 presidente da província sabia, por todos os seus correspondentes locais, da falta de armamentos, munição e pessoal. Sabia das cadeias de péssima construção, facilitando fugas a não ser que um destacamento ficasse de vigia. As condições eram bastante precárias, como dizia o subdelegado de Buique no dia 3 de janeiro, "a minha ronda que vigiava o sossego público desta povoação uniu-se aos sediciosos" e ainda "nesta Subdelegacia não há um só tiro, nem armamento algum²3".

Como mostrou Palacios, não podiam confiar na Guarda Nacional,

"(...) porquanto a G.Nacional é a que constitui a força dos sediciosos, e quando o não fosse, o seu estado de completa indisciplina e insubordinação a indiferença que se manifestou ao movimento armado, nenhuma garantia podem oferecer24".

E essa opinião era unânime entre os delegados e juizes. Ainda que o Presidente da Província insistisse nos destacamentos da Guarda, todos pediam pelas forças de linha. Mas não havia tropa de linha suficiente para enviar a todas as localidades e mantê-las por algum período na vigilância. E isso numa época em que vários lugares da Província ainda mantinham destacamentos, tendo em vista os recentes abalos, como a perseguição ao bando de Pedro Ivo (preso no final de 1850).

Há, por parte das autoridades do centro (Recife) a percepção da precariedade das forças militares e a consciência da necessidade de aprimorar essa força, sobretudo enfrentando a questão do recrutamento. Em seu livro Campesinato e escravidão Palacios estuda o recrutamento durante a colônia e mostra o secular horror dos homens livres pobres - 
Guillermo Palacios, Campesinato e escravidão no Brasil: agricultores livres pobres na Capitania Geral de Pernambuco (1700-1817), Brasília: Edunb, 2004.

\section{6}

Matthias Röhrig Assunção, "Elite politics and popular rebellion in the construction of post-colonial order. The case of Maranhão, Brazil (1820-41)". Journal of Latin American Stuadies, v. 31, fevereiro de 1999.

\section{7}

F. W. O. Morton., The conservative revolution of independence: economy, society and politics in Bahia, 1790-1840. Tese de doutorado apresentada à Universidade de Oxford, 1974. principal manancial de recrutas - de prestar serviço militar, as estratégias utilizadas para escapar da polícia, causando abandono de plantações e desestruturando o abastecimento alimentar ${ }^{25}$. Esse foi um foco de tensão durante a colônia.

Outra questão importante para Palácios é a importância da Praieira na compreensão da Guerra dos Maribondos. Afirma que a revolta foi um pretexto para unir e não dividir as elites locais. As desavenças políticas da época da praieira eram nesse contexto menos importantes.

Esse é um dos pontos fundamentais, a relação de causa e efeito entre elites divididas e dificuldade de controle popular. Essa também foi a percepção do Mathias R. Assunção, como um dos fatores importantes para compreender a Balaiada 26 , e pode ajudar a pensar o caso baiano, se concordarmos com a formulação de Morton que as elites formavam um verdadeiro cordão sanitário mantendo o recôncavo sob controle 27 .

Estavam unidas no combate, mas estariam mesmo tão interessadas na aplicação da lei? Ai parece estar uma questão central. Se a lei do Censo fosse estratégica, como os discursos parlamentares faziam parecer, será que o gabinete mais forte do império teria revogado a lei sem partir para a ofensiva?

Para quem interessava, de fato, a lei do Censo? Ou melhor, para quem não interessava? Os documentos pesquisados não deram ainda pistas nesse sentido. Mas podemos conjecturar que nesse quadro de dificuldade de controle da mão de obra livre talvez não fosse interessante aos senhores de engenho expor suas possiveis clientelas, para não serem, por exemplo, recrutáveis, ou também não exporem os escravos havidos ilegalmente após 1831 e até após 1850 (pois ainda durante 1851 e 1852 ocorriam esporádicos desembarques na costa pernambucana). 0 Censo e o registro eram úteis, eram importantes, mas não eram prementes, não eram, para aquelas elites, imprescindiveis, tanto que aguardaram até 1872 sem maiores transtornos. Isso porque havia escravos. Em 1872, depois da Lei do Ventre Livre, a situação já era outra. Mera coincidência os dois projetos nacionais de Censos estarem colados a leis relacionadas à escravidão - 1850, fim do tráfico, 1872, ventre-livre?

Já no final do século XVIII essa associação era feita, como mostra Palacios em seu livro. A população livre e pobre já desconfiava do censo há duas gerações, mas pelo visto tampouco aos senhores da terra parecia interessante.

Esta é uma questão que fica em aberto no texto de Palácios: não houve repressão por dificuldades estratégicas - que eram reais - ou há outros cálculos políticos por trás, tendo em vista que o Estado soube ser violento antes, como na repressão à Guerra dos Cabanos e à Praieira, para citar as mais importantes. E saberia ser muito violento depois, na sanguinária repressão ao Quebra-Quilos. A Guerra dos Marimbondos encontrou ampla adesão dentro da Guarda Nacional, o que talvez complicasse muito as coisas. Mas talvez a questão central esteja no cálculo político do novo gabinete.

Era interessante para o gabinete da ordem armar uma guerra no país, em diversas frentes, justamente nesse contexto da recente pacificação da praieira, quando bradavam a vitória e a paz aos quatros cantos? Ou seria melhor fazer a sedição desaparecer da história, movimento completamente popular, que evidenciava a capacidade de ação de homens desde sempre considerados fora da política, fora da história? Diante das inúmeras leis 
aprovadas em 1850-1851, diante do esforço em controlar o fim do tráfico, impor o Código Comercial, valia a pena a mobilização militar para fazer a contagem da população do país, que afinal de contas podia acabar expondo escravos ilegais, currais eleitorais fictícios, redes clientelares manipuláveis? Não era preciso ganhar essa batalha para vencer a guerra.

\section{Versões de nossa história}

Como diz o próprio Palacios, a revolta talvez tenha sido pouco estudada por não ter tido a importância de outras, mas mesmo as outras foram pouco estudadas, se compararmos, por exemplo, com o abolicionismo, para pensar em movimentos sociais. Qual o pensamento que está por trás desse relativo silêncio da historiografia com relação aos movimentos populares?

A idéia dominante é a de que no Brasil não houve movimentos populares significativos, ou foram movimentos de elite com participação popular, ou movimentos de caráter religioso, destituídos de reivindicação política. Lembremos, para o Diário a revolta não teria durado uma semana, começado em primeiro de janeiro e acabado com a chegada do frade, no dia cinco. Nos jornais, os ilustrados diziam por exemplo que os padres teriam incensado os povos para se rebelarem, e esse me parece ser mais um motivo buscado fora da experiência dos sujeitos em luta. Os padres teriam medo de perder o rendoso negócio de batismos e enterramentos, mas seria mesmo rendoso, tendo em vista a maioria da clientela? Em Limoeiro o padre foi incansável na tentativa de acalmar os ânimos, em Bom Jardim foi representar o governo falando com os revoltosos armados, em freguesias distantes o padre arriscava a vida indo rezar missa para dissuadir os povos, e alguns foram mesmo alvo das armas. Em Vitória o padre causou a maior confusão quando disse em fevereiro que o regulamento teria de ser aplicado e começa a agir nesse sentido - não me parece que os padres tenham tido papel no encorajamento do povo à revolta, essa idéia está nos relatórios governamentais, mas parece uma desculpa, uma busca por uma explicação lógica, palpável.

A crer nesses testemunhos, nessas versões da história, teriamos a impressão de que o ambiente era calmo, de quando em vez alguns tentavam sublevar a plebe mas era esporádico - desenha-se um país sem maiores conflitos.

A Guerra dos Marimbondos, como disse Palacios, foi um movimento sem líderes que uniu agricultores pobres autônomos, agregados, jornaleiros, brancos ao lado de negros, mulheres ao lado de homens. 